\title{
TERMINAL BRANCHES OF THE AORTA IN WHITE-LIPPED PECCARY (Tayassu pecari Link, 1795)
}

\author{
MACHADO, G.V. ${ }^{1}$; GONÇALVES, P.R. ${ }^{2}$; PARIZZI, A. ${ }^{2}$; TAFAREL, M. ${ }^{3}$; \\ UTIUMI, K.U. ${ }^{3}$; WIEZBICKI, M. ${ }^{3}$ \\ ${ }^{1}$ UFPR/Campus Palotina; \\ ${ }^{2}$ UPF (Universidade de Passo Fundo); \\ ${ }^{3}$ Graduandos - UFPR/Campus Palotina.
}

The white-lipped peccary (Tayassu pecari) belongs to the Tayassuidae family. It is found from the South of the USA to the far South of Argentina. Parallel to the interest about the creation of this animals in captivity, several groups of researchers are working on aspects of its physiology,including digestion, reproduction, among others. In the present research work, it is aiming to offer subsidies to the knowledge of peccary's morphology a research line set up at the UFPR/Campus Palotina Laboratory of Veterinary Anatomy as a special support to other applied sciences and to the better knowledge of those animals, their rational exploration and protection in the nature. The main objective of the present work has been to detail the anatomical behavior of the peccary's aorta terminal branches, their importance in the blood supply of the pelvic organs and to the pelvic members, trying to correlate this knowledge to those already registered for other species. Six animals - adult males and females - from authorized nurseries, were used in the presente study. They had their arterial vascular system injected with a colored solution of Neoprene latex. After this step, they were fixed in a $10 \%$ formalin aqueous solution and then dissected. The dissection was guided towards the exhibition of the pelvic cavity allowing to unreveal the behavior of the arterial branches originating from the aorta. It has been seen that a) the aorta, at the level of the last lumbar vertebra, becomes separated in external iliac arteries, right and left, and, after a short trunk, the internal iliac arteries, right and left. Their primary division does not emits, therefore, a median sacral artery; b) each external iliac artery emits, in a symmetrical way, the deep circumflex artery of the ileo emiting after the femoral and deep femoral arteries. This last one emits, as first branch, the pudendoepigastric trunk; c) already the internal iliac arteries, also in a symmetrical way, after originating the round ligament of the urinary bladder, send a vaginal artery and a middle uterine artery, finishing for the bifurcation in caudal gluteal and internal pudendal arteries. The vaginal artery, for iits turn, becomes separated in vaginal and uterine branches.

Key Words: anatomy, blood supply, white-lipped peccary, Tayassu pecari. 